\title{
EFFECT OF ROSELLE SEEDS FLOUR ADDITION ON THE QUALITY CHARACTERISTICS OF PAN BREAD \\ Abdulla, G. ${ }^{*}$ and M.A.S. Abdel-Samie ${ }^{* *}$ \\ *Food Sci. Dept., Fac. Agric., Zagazig Univ., Egypt \\ ${ }^{\star \star}$ Food and Dairy Sci. and Tech. Dept., Fac. Environmental \\ Agric. Sci., Suez Canal Univ., Egypt.
}

\begin{abstract}
The effect of defatted Roselle seeds flour (DRSF) addition at different levels (5, 10 and $15 \%$ ) to wheat flour on the flour characteristics, dough rheological properties, bread chemical, physical and sensory characteristics were investigated. Mixolab analysis showed that the addition of DRSF led to a reduction in the flour water absorption and an increase in the dough development time and consequently decreased the dough stability compared to the control. Also, the addition of DRSF decreased the bread loaf volume and increased its protein and fibers contents and the antioxidant activity compared to the control. Sensory evaluation showed that all fortified bread samples were acceptable up to $10 \%$ DRSF.

Keywords: Bread fortification, Roselle seed flour, Rheological properties, Mixolab.
\end{abstract}

\section{INTRODUCTION}

Bread is considered the most famous backed products in the world, its quality is affected by several factors including flour type, and additives (Dall'Asta et al., 2013). Wheat flour is rich source of energy, dietary fiber, minerals, vitamins and many other bioactive compounds, and no other cereal flour could achieve its baking properties. Wheat flour protein is deficient in some essential amino acids such as lysine and threonine. Fortification of wheat flour with protein-rich materials including cereal and non-cereal sources had been applied by many researchers to improve its protein content and quality and to add more bioactive compounds to the resultant baked products, especially bread, and to prevent worldwide protein-energy malnutrition. Consumer acceptability of new developed products is a key point of its success. (Amir et al., 2013 and Ogur, 2014).

Roselle (Hibiscus sabdariffa L.), regionally known as karkade, is an important annual plant belongs to Family Malvaceae (Yagoub et al., 2008). Roselle grows successfully in tropical and sub-tropicals. Roselle seeds contained $30.6-35.4 \%$ protein, $22.1-29.6 \%$ lipids, $26-33 \%$ carbohydrates and $18.3-25.5 \%$ total dietary fiber and high minerals contents including potassium, magnesium and calcium. Roselle seed protein is rich in lysine, arginine, leucine, phenylalanine and glutamic acid. Roselle seeds were indicated to be a potential source of functional ingredients (Hainida et al., 2008b). Amino acids pattern of Roselle seeds is higher than FAO/WHO (1974) requirement, seeds protein fractions and isolates (with its low molecular weight poly peptide) are considered as functional ingredients with high nutritional properties (Tounkara et al., 2013). Defatted dried roselle seeds lowered 
plasma cholesterol and low density lipoprotein cholesterol levels in rats with induced hypercholesterolemia (Hainida et al., 2008a). Roselle seeds are a good source of lipid-soluble antioxidants, particularly $\mathrm{Y}$-tocopherol and Vitamin E. The seeds contained total tocopherols of $2000 \mathrm{mg} / \mathrm{kg}$, including $\alpha$ tocopherol (25\%), y-tocopherol (74.5\%), and $\delta$-tocopherol (0.5\%) (Mohamed et al., 2007). These antioxidants reduced lipid oxidation in food and were better when compared to Butylated hydroxytoluene (BHT) (Mohd-Esa et al., 2010).

This study aimed to investigate the effect of defatted Roselle seeds flour (DRSF) on the quality properties of pan bread

\section{MATERIALS AND METHODS}

Commercial wheat flour (72\% extract), and baking ingredients were purchased from the local markets of Zagaig city, El-Sharquia governorate, Egypt. Roselle (Hibiscus sabdariffa L.) seeds were obtained from the Agricultural Research Center, Giza, Egypt.

\section{Preparation of Roselle seeds Flour}

Roselle seeds were cleaned, dried in shade and ground into powder using a grinder (Moulinex, France). Roselle seeds flour was defatted by soxhlet extraction using $n$-hexane as a solvent. The solvent was removed by hot air drying at $\left(45^{\circ} \mathrm{C} \pm 1\right)$ for 12 hours. The Defatted Roselle seeds flour (DRSF) was sieved through a 60 mesh screen until fine powder was obtained and kept frozen at $-18^{\circ} \mathrm{C}$ in polyethylene pages until used.

Flour quality

Mixolab (Chopin, Tripette and Renaud, Villeneuve-la-Garenne, France) was used to analyze flour quality as described by Jia et al. (2011).

\section{Bread preparation}

Pan bread preparation was based on the official method 10-09 (AACC, 2002) with some modifications. The formula of control pan bread is reported in Table (1). The addition levels of DRSF were $5 \%, 10 \%$ and $15 \%$ based on wheat flour. Water, salt, sugar, oil, fermented starter and dry yeast were added and mixed in Kenwood Major mixer (Kenwood, Hampshire, UK) at medium speed for $2 \mathrm{~min}$. Flour was added and mixed at high speed for 6 min. After the mixing time, the dough was divided into $750 \mathrm{~g}$ pieces and put into 30 $\times 10 \times 10 \mathrm{~cm}$ baking pans. Then, the pans were rested in trays at room temperature for $10 \mathrm{~min}$, it was covered by a plastic film to prevent dehydration during proofing. The pans were placed in a thermostatically controlled proofing oven at $35^{\circ} \mathrm{C}$ and $95 \%$ relative humidity for 45 minutes for final proofing. Baking was performed in an electrical oven at $200^{\circ} \mathrm{C}$ for 30 minutes. Bread loaves obtained were cooled to $25^{\circ} \mathrm{C}$ for 3 hours before use in further evaluation. 
Table 1. Control dough of pan bread formula

\begin{tabular}{|l|c|}
\hline Ingredient & Weight (g) \\
\hline Flour & 1000 \\
Sugar & 50 \\
Oil & 40 \\
Fermented starter & 150 \\
Dry yeast & 30 \\
Salt & 5 \\
Water & 600 \\
\hline Total & 1875 \\
\hline
\end{tabular}

\section{Sensory evaluation:}

Bread samples with or without DRSF were organoleptically evaluated for aroma, crust color, crumb color, texture, taste and overall acceptability according to Tuorila (2015). Bread samples were introduced in random order to 35 untrained panelists (staff of Food Science Department, Faculty of Agricultural, Zagazig University, Egypt) within 24 hours of bread preparation. The panelists were chosen randomly and the samples were subjected to sensory evaluation using a 9-point hedonic scale, where ( $1=$ dislike extremely, $2=$ dislike very much, $3=$ dislike moderately, $4=$ dislike slightly, $5=$ neither like nor dislike, $6=$ like slightly, $7=$ like moderately, $8=$ like very much, and $9=$ like extremely, and the mean of 35 values was taken.

Physical properties of bread:

Specific Volume:

Volume of bread loaves was measured using Tex-vol instrument BVM-L370. Specific volume of bread was calculated from the ratio between volume and weight of loaves (Sciarini et al., 2012).

Texture analysis:

Fresh bread samples supplemented with different levels of DRSF (5, 10 and $15 \%$ ) were analyzed for their texture profile (hardness, stickiness, adhesiveness, chewiness, cohesiveness, gumminess, springiness and stringiness) according to the methods described by O'Brien et al., (2000) with minor modifications. Texture analyzer (TVT-300XP) was used on two bread slices of $12 \mathrm{~mm}$ height (24 mm total), two compression cycles with 5 seconds relaxation; the probe was a $35 \mathrm{~mm}$ cylindrical coded (P-Cy35S), compression cell $5 \mathrm{~kg}$, pretest speed $5 \mathrm{~mm} / \mathrm{min}$, compression rate $40 \%$ of original height, force in grams required to accomplish compression was recorded as hardness.

Proximate chemical composition:

Proximate chemical composition of crude DRSF as well as prepared pan bread was determined. Moisture, ash contents were determined according to the approved method of AACC (2002). Crude protein and fiber contents were determined according to AOAC (2005).

Antioxidant activity:

Antioxidant properties including extraction of flour and DPPH scavenging activity percentage of flour samples, defatted Roselle seeds flour and all treated bread samples were determined according to Lilei et al. (2013). 


\section{Statistical analysis:}

Analysis of variance (ANOVA) was used by SAS software version 9.2 (SAS Institute, 1990). Differences between means were determined by the least significant difference test, and significance was defined at $P<0.05$. All measurements were carried out in triplicates.

\section{RESULTS AND DISSCUSSION}

\section{Flour characteristics and dough rheological properties:}

Rheological properties of composite flour characteristics are shown in Table 2. The moisture content of the flour ranged from $12.70 \%$ for $15 \%$ DRSF to $13.62 \%$ for control. Water absorption of flour, one of its fundamental quality parameters, can be defined as the amount of water needed to hydrate flour to produce dough with optimum consistency. Water absorption of wheat flour was influenced by the extraction rate, protein (gluten) content, starch properties (damaged and gelatinized starch granules) and flour particle size (Perten, 1990). Water absorption of control wheat flour was $56.17 \%$. Proportional addition of DRSF to wheat flour decreased the water absorption values comparing to that of the control. Wheat flour with $15 \%$ DRSF had the lowest water absorption value (51.2\%). The decrease in water absorption capacity of DRSF may be related to the denaturation of protein during the defatting or fat trimming process. Rakszegi et al. (2014) stated that water absorption of wheat flour was affected by soluble protein and damaged starch contents. Similar results were reported by Sibanda et al. (2015), since they found that a decrease in the water absorption ability of the flour from $57.73 \%$ for $100 \%$ wheat to $53.03 \%$ for the $30 \%$ sorghum flour.

Dough development time (DDT) (C1 time in Table 2) of control treatment was ideal as it was minimal at a time of 1.42 minutes while the addition of DRSF increased DDT to reach $4.11,5.31$ and 6.23 minutes in 5, 10 and $15 \%$ DRSF, respectively. This might be due to the dilution of wheat gluten by the addition of gluten free additive (DRSF) and also is due to the higher fiber contents in DRSF comparing to wheat flour. Those findings were similar to those found by Sedej et al. (2011), who reported an increased in DDT with higher fiber additives to bread flour.

Table 2. Rheological properties of control and composite wheat flour measured using Mixolab

\begin{tabular}{|l|c|c|c|c|}
\hline Properties & $\begin{array}{c}\text { Flour } \\
\text { moisture } \\
\text { (\%) }\end{array}$ & $\begin{array}{c}\text { Water } \\
\text { absorption } \\
\text { (\%) }\end{array}$ & $\begin{array}{c}\text { Dough } \\
\text { development } \\
\text { time (min.) }\end{array}$ & $\begin{array}{c}\text { Dough } \\
\text { Stability } \\
\text { (min.) }\end{array}$ \\
\hline Control & $13.62 \mathrm{a}$ & $56.17 \mathrm{a}$ & $1.42 \mathrm{~d}$ & $8.95 \mathrm{a}$ \\
\hline $\mathrm{R} 5$ & $13.10 \mathrm{~b}$ & $53.70 \mathrm{~b}$ & $4.11 \mathrm{c}$ & $8.22 \mathrm{~b}$ \\
\hline $\mathrm{R} 10$ & $12.93 \mathrm{c}$ & $51.82 \mathrm{c}$ & $5.31 \mathrm{~b}$ & $7.82 \mathrm{c}$ \\
\hline $\mathrm{R} 15$ & $12.70 \mathrm{~d}$ & $51.20 \mathrm{~d}$ & $6.23 \mathrm{a}$ & $7.3 \mathrm{~d}$ \\
\hline
\end{tabular}

R5: 5\%DRSF, R10: 10\% DRSF, R15: 15\% DRSF 
Dough stability represents the period of time in which the dough is able to stand with the applied deformation, subsequent decrease in torque value during further kneading and heating is measure of protein weakening (Rosell et al., 2007). Application of DRSF to the flour caused a decrease in dough stability from 8.95 minutes in control flour to $8.22,7.82$ and 7.3 minutes in 5 , 10 and $15 \%$ DRSF, respectively. This decrease in dough stability was also noted by Sibanda et al. (2015) who reported a decreased dough stability with the addition of sorghum to the dough.

\section{Sensory evaluation}

Sensory evaluation is considered to be one of the limiting factors for consumer acceptability. Sensory evaluation of control and DRSF enriched breads (aroma, crust and crumb colors, texture, taste and overall acceptability) is shown in Table (3) and Figure (1).

Gradual increase in DRSF addition percentage to bread decreased aroma scores from 9.1 in control to $8.6,8.2$ and 8 in the 5, 10 and $15 \%$ added DRSF. Color of bread including crust and crumb color scores decreased with the proportional increase in DRSF. Texture of the DRSF added bread samples got lower scores $(7.8,6.2$ and 5.6 for 5,10 and $15 \%$ added DRSF respectively), which comes in agreement in texture profile results in Table 4. As the bitter taste of DFRS affected the taste of prepared bread, sensory scores of taste of bread decreased from 8.5 in control sample to 8.2, 7.0 and 5.8 in the 5, 10 and $15 \%$ added DRSF bread samples, respectively.

Pan bread containing 15\% DRSF had the lowest overall acceptability score (5.8) compared to control (8.4) and was not favored by most of the panelists because of the bitter taste, while the 5 and $10 \%$ of added DRSF was preferred and accepted for panelist comparing to the $15 \%$ added DRSF bread with scores of 8.2 and 7.2, respectively. These results are in harmony with these found by Lee and Choi (2013).

Table 3. Sensory evaluation of pan bread treated with DRSF

\begin{tabular}{|l|c|c|c|c|c|c|}
\hline Properties & $\begin{array}{c}\text { Aroma* } \\
\mathbf{( 9 )}\end{array}$ & $\begin{array}{c}\text { Crust } \\
\text { color } \\
\mathbf{( 9 )}\end{array}$ & $\begin{array}{c}\text { Crumb } \\
\text { color } \\
\mathbf{( 9 )}\end{array}$ & $\begin{array}{c}\text { Texture } \\
\mathbf{( 9 )}\end{array}$ & $\begin{array}{c}\text { Taste } \\
\mathbf{( 9 )}\end{array}$ & $\begin{array}{c}\text { Overall } \\
\text { Acceptability } \\
\mathbf{( 9 )}\end{array}$ \\
\hline Control & $9.1 \mathrm{a}$ & $8.9 \mathrm{a}$ & $8.7 \mathrm{a}$ & $8.7 \mathrm{a}$ & $8.5 \mathrm{a}$ & $8.4 \mathrm{a}$ \\
\hline $\mathrm{R} 5$ & $8.6 \mathrm{a}$ & $8.0 \mathrm{ab}$ & $8.4 \mathrm{a}$ & $7.8 \mathrm{a}$ & $8.2 \mathrm{a}$ & $8.2 \mathrm{ab}$ \\
\hline $\mathrm{R} 10$ & $8.2 \mathrm{ab}$ & $7.5 \mathrm{~b}$ & $6.6 \mathrm{~b}$ & $6.2 \mathrm{~b}$ & $7.0 \mathrm{~b}$ & $7.2 \mathrm{~b}$ \\
\hline $\mathrm{R} 15$ & $8.0 \mathrm{~b}$ & $5.8 \mathrm{c}$ & $6.0 \mathrm{~b}$ & $5.6 \mathrm{~b}$ & $5.8 \mathrm{c}$ & $5.8 \mathrm{c}$ \\
\hline
\end{tabular}

R5: 5\%DRSF, R10: 10\% DRSF, R15: 15\% DRSF

- all parameters were given a score on 9 points headonic scale 

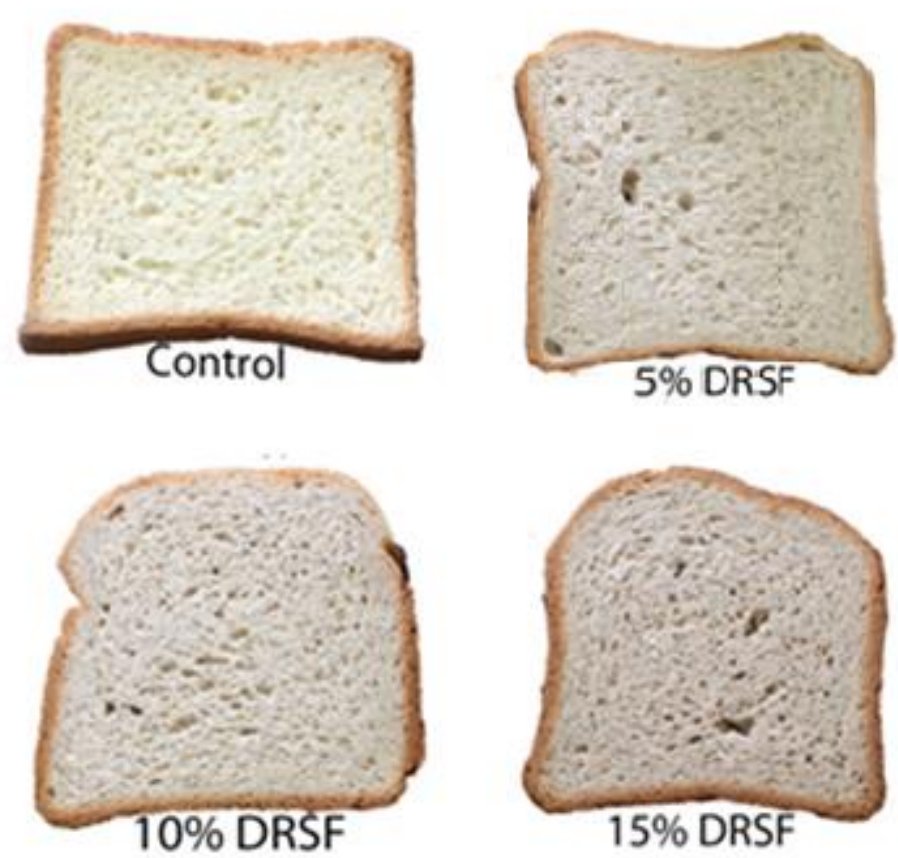

Figure 1. Images of control and enhanced pan bread with the DRSF

\section{Physical properties of bread:}

Physical properties of control and DRSF enhanced bread including bread texture, loaves specific volumes, bread hardness, stickiness, adhesiveness, chewiness, gumminess, springiness, and stringiness as well as bread color are presented in Table (4).

As for specific volumes of control and DRSF treatments, control bread had the highest specific volume $(2.83 \mathrm{~g} / \mathrm{cm} 3)$ with a perfect texture and best gluten network comparing to other samples, while $15 \%$ DRSF had the lowest specific volume $(2.47 \mathrm{~g} / \mathrm{cm} 3)$. A significant reduction in loaf volume was observed as the levels of DRSF increased. Lower specific volume values of bread with the addition of DRSF may be due to the lower gluten content in the additives (DRSF) which gives less active gluten network and gas trapping (Doxastakis et al., 2002).

Texture is a manifestation of the rheological properties of a food product, texture then affects processing, handling, shelf stability and consumer acceptance of food products (Agyare et al., 2005). Texture of bread slices was analyzed and all texture parameters merged from the texture analyzer curves are reported in Table (4).

Hardness is the peak force of the first compression of the product or force required to compress a food between the molars, defined as force necessary to attain a given deformation (40\%). Those definitions describe the 
first bite feeling in mouth. From the data it can be noticed that the addition of different levels of DRSF gradually increased hardness values. Control treatment showed the lowest hardness $(6108 \mathrm{~g})$, while the addition of 5, 10 and $15 \%$ of DRSF gradually increased bread hardness values to 6814,7834 and $8532 \mathrm{~g}$, respectively. These results may be attributed to the lower loaves volume of DRSF enhanced bread compared to the control which made the bread components more condensed therefore it gave harder texture. It was found that the smaller loaf volume has a negative effect on its quality attributes, such as crumb grain and tenderness (Doxastakis et al. 2002).

Table 4. Physical properties of pan bread treated with DRSF

\begin{tabular}{|c|c|c|c|c|}
\hline \begin{tabular}{|ll} 
Properties & Treatment \\
\end{tabular} & Control & R5 & R10 & R15 \\
\hline Volume $\left(\mathrm{cm}^{3}\right)$ & $1892 \mathrm{a}$ & $1788 \mathrm{~b}$ & $1699 c$ & $1638 \mathrm{~d}$ \\
\hline Weight $(\mathrm{g})$ & $667.77 \mathrm{~b}$ & $673.87 a$ & $668.02 b$ & $663.19 \mathrm{~b}$ \\
\hline Specific volume (g/cm3) & $2.83 \mathrm{a}$ & $2.65 \mathrm{~b}$ & $2.54 \mathrm{c}$ & $2.47 d$ \\
\hline Hardness (g) & $6108 \mathrm{~d}$ & $6814 \mathrm{c}$ & $7834 \mathrm{~b}$ & $8532 \mathrm{a}$ \\
\hline Stickiness (g) & 1511d & $1671 \mathrm{c}$ & $2345 \mathrm{~b}$ & $2570 \mathrm{a}$ \\
\hline Adhesiveness & $3502 d$ & $3719 \mathrm{c}$ & $3917 \mathrm{~b}$ & $4377 \mathrm{a}$ \\
\hline Chewiness (g) & $1227 d$ & $1818 \mathrm{c}$ & $2264 b$ & $2617 a$ \\
\hline Cohesiveness & $0.44 \mathrm{c}$ & $0.51 \mathrm{~b}$ & $0.52 a b$ & $0.53 a$ \\
\hline Gumminess (g) & $2634 d$ & $3441 c$ & $4020 \mathrm{~b}$ & $4475 a$ \\
\hline Springiness & $0.48 \mathrm{~d}$ & $0.54 \mathrm{c}$ & $0.57 \mathrm{~b}$ & $0.59 \mathrm{a}$ \\
\hline
\end{tabular}

R5: 5\%DRSF, R10: 10\% DRSF, R15: 15\% DRSF

As it mentioned above, hardness is the first positive peak force as bread resist compression by the probe, exactly the same when it resist compression under teeth, while the negative peak simulate the stickiness or adhesiveness of bread samples to teeth. Adhesiveness is defined as the work necessary to overcome the attractive forces between the surface of the food and the surface of other materials with which the food comes into contact (e.g. tongue, teeth, palate), or the work required to pull food away from a surface. It was noticed that stickiness values had the same trends of hardness values. That might be because of the higher contents of protein in roselle seeds flour, comparing to wheat flour. Increased stickiness with increased protein contents were also reported by Zhu et al., (2001) who found that, stickiness of steamed bread and dough were higher with the gradual increase of protein contents.

Gluten dilution by the addition of DRSF caused less active gluten network and a less gas trapping within dough caused decreased gas to whole volume ratio which led to an increase in hardness of bread samples. Increase in hardness through the compression and decreased gas trapping and increased stickiness makes bread samples more chewable as could also be easily merged from data in Table (4).

Chewiness is the chewing ability of bread slices samples; it can be calculated from the texture analyzer (TVT-300XP) software from multiple 
analyses of gumminess and springiness. Following the increased of both parameters gumminess and springiness, chewiness of bread enhanced with DRSF were higher than control samples. Control bread sample recorded the lowest chewiness value (1227 g), while 15\% DRSF gave the highest being $2617 \mathrm{~g}$. The addition of different levels of DRSF gradually increased chewiness, Table (4).

Cohesiveness is how well the product withstands a second deformation relative to how it behaved under the first deformation. It is measured as the area of work during the second compression divided by the area of work during the first compression. The same trend of all texture parameters was also reported in cohesiveness which ranged between 0.44 to 0.53 for control and $15 \%$ DRSF enhanced bread, respectively.

Springiness measure the recovery of food structure after it has been deformed during the first compression (Guine and Barroca, 2012). Data showed that the springiness gradually increased with the addition of DRSF from 0.48 in control bread to $0.54,0.57$ and 0.59 in the 5, 10 and 15\% DRSF enhanced bread, respectively. Also, an increase in cohesiveness and springiness as well were clearly observed when DRSF was applied to bread formula. These results agree with those reported by Onyango et al. (2015).

\section{Proximate chemical composition:}

Crude DRSF contains $9.21 \%$ moisture, $33.45 \%$ protein, $1.04 \%$ fat, $5.17 \%$ ash, $4.42 \%$ crude fiber and $46.72 \%$ total carbohydrate

Proximate chemical composition of control and DRSF enhanced bread are shown in Table (5). The results indicated that the moisture contents of all bread samples gradually decreased compared to control (41.3\%). The addition of 5,10 and $15 \%$ of DRSF decreased the bread moisture content to $37.66,36.21$ and $35.6 \%$, respectively. The high protein content of crude DRSF used in the fortification of the wheat flour was reflected in the high content of protein in the produced bread. Protein content ranged from $12.11 \%$ in control to $15.36 \%$ in $15 \%$ added DRSF. The addition of DRSF to wheat flour was expected to increase protein content of produced bread, science they have high content of protein (33.45\%). Similar findings were observed by Anton et al. (2008) who stated that the addition of bean flour to wheat flour was expected to increase the protein content of tortillas, since legumes generally contain more proteins than cereals.

Table 5. Proximate composition of pan bread treated with DRSF

\begin{tabular}{|l|c|c|c|c|}
\hline \multicolumn{1}{|c|}{ Constituents } & Moisture & Protein & Fiber & Ash \\
\hline Treatment & & & & \\
\hline Control & $41.30 \mathrm{a}$ & $12.11 \mathrm{~d}$ & $1.05 \mathrm{~d}$ & $0.70 \mathrm{~d}$ \\
\hline R5 & $37.66 \mathrm{~b}$ & $13.65 \mathrm{c}$ & $2.93 \mathrm{c}$ & $0.84 \mathrm{c}$ \\
\hline $\mathrm{R} 10$ & $36.21 \mathrm{c}$ & $14.11 \mathrm{~b}$ & $3.60 \mathrm{~b}$ & $0.90 \mathrm{~b}$ \\
\hline $\mathrm{R} 15$ & $35.60 \mathrm{~d}$ & $15.36 \mathrm{a}$ & $4.25 \mathrm{a}$ & $0.98 \mathrm{a}$ \\
\hline
\end{tabular}

R5: 5\%DRSF, R10: $10 \%$ DRSF, R15: $15 \%$ DRSF

Control bread sample had the lowest ash content $(0.70 \%)$ comparing to those of other enhanced bread samples. As the levels of DRSF increased in 
bread as its ash content increased to reach $0.98 \%$ in the $15 \%$ added DRSF. Roselle flour contained $4.42 \%$ fiber. Fiber contents of enhanced breads were higher than control bread samples which contained $1.05 \%$. DRSF gradually increased fiber contents to be 2.93, 3.6 and $4.25 \%$ in 5,10 and $15 \%$ added DRSF, respectively. These results are closed to that found by Seleem \& Omran (2014) who stated that bread enhanced with beans had the highest values in protein, ash and fiber compared with wheat and sorghum bread.

\section{Antioxidant activity:}

Table. (6) shows the total phenolic compounds and antioxidant properties of bread samples as well as the raw materials used. Results of total phenolic compounds (TPC) in raw materials were found to be $5.25 \mathrm{mg}$ gallic acid equivalent $/ 100 \mathrm{~g}(\mathrm{GAE} / 100 \mathrm{~g})$ in wheat flour, while TPC of DRSF was higher (10.41 mg Gallic acid equivalent/100g). DPPH scavenging activity of wheat flour and DRSF were 64.3 and $89.5 \%$, respectively. Control bread contained the lowest TPC content $(1.03 \mathrm{mg} \mathrm{GAE} / 100 \mathrm{~g})$, while samples contained $15 \%$ DRSF had the highest TPC content of $1.41 \mathrm{GAE} / 100 \mathrm{~g}$ bread.

DPPH scavenging activity percentages of bread samples are presented in Table (6). Bread samples with $15 \%$ of DRSF had the highest DPPH scavenging percentage $(90.4 \%)$, while control bread had the lowest $(82.1 \%)$. It was noticed that, the addition of DRSF increased the DPPH scavenging percentages. Similar results are found by Swieca et al. (2014) who reported that fortification of bread with coriander and quinoa leaves powder enhanced the antioxidant properties and phenolic content of bread.

Table 6. Antioxidant activity of pan bread treated with DRSF

\begin{tabular}{|l|c|c|}
\hline \multicolumn{1}{|c|}{ Antioxidant } & $\begin{array}{c}\text { TPC } \mathbf{~ m g} \\
\text { Gallic acid equivalent/g }\end{array}$ & $\begin{array}{c}\text { DPPH } \\
\text { Scavenging Activity \% }\end{array}$ \\
\hline Wheat flour & 5.25 & 64.3 \\
\hline DRSF & 10.41 & 89.5 \\
\hline Control & $1.03 \mathrm{~d}$ & $82.10 \mathrm{~d}$ \\
\hline R5 & $1.14 \mathrm{c}$ & $87.37 \mathrm{~b}$ \\
\hline R10 & $1.29 \mathrm{~b}$ & $88.20 \mathrm{~b}$ \\
\hline R15 & $1.41 \mathrm{a}$ & $90.40 \mathrm{a}$ \\
\hline
\end{tabular}

\section{CONCLUSION}

Enhancement of wheat flour with DRSF decreased water absorption and weakened the rheological properties of the dough though the diluting and disrupting the gluten network. The loaf volume was significantly decreased, while hardness, cohesiveness and springiness increased as the levels of DRSF increased. The addition of DRSF led to slightly darker crumb (lower $L^{*}$ values) than control. Bread sample enhanced with DRSF was acceptable by panelists up to $10 \%$. We recommend the application of DRSF in bread up to $10 \%$ to enrich its nutritional value and antioxidant activity without reducing consumers' acceptability. 


\section{REFERENCES}

AACC, I. (2002). Approved Methods of Analysis, Baking Quality. Basic Straight-Dough Bread-Baking Method-Long Fermentation, Method 1009. AACC International, St. Paul, MN, U.S.A., Approved November 3, 1999.

Agyare, K.; K. Addo; Y. Xiong; and C. Akoh (2005). Effect of structured lipid on alveograph characteristics, baking and textural qualities of soft wheat flour. Journal of Cereal Science, 42: 309-316.

Amir, I. Z.; H. S. Hanida and A. Syafiq (2013). Development and physical analysis of high fiber bread incorporated with cocoa (Theobroma cacao sp.) pod husk powder. International Food Research Journal, 20: 13011305.

AOAC. (2005). Official Methods of Analysis of the Association of Official Analytical Chemists, 18th ed., AOAC International, Arlington, Virginia, USA.

Anton, A. A.; K. A. Ross; O. M. Lukow; R. G. Fulcher and S. D. Arntfield (2008). Influence of Added Bean Flour (Phaseolus vulgaris L.) on Some Physical and Nutritional Properties of Wheat Flour Tortillas. Food Chemistry, 109: 33-41.

Dall'Asta, C.; M. Cirlini; E. Morini; M. Rinaldi; T. Ganino and E. Chiavaro (2013). Effect of chestnut flour supplementation on physico-chemical properties and volatiles in bread making. LWT - Food Science and Technology, 53: 233-239.

Doxastakis, G.; I. Zafiriadis; M. Irakli; H. Marlani and C. Tananaki (2002). Lupin, soya and triticale addition to wheat flour doughs and their effect on rheological properties. Food Chemistry, 77, 219-227.

FAO/WHO. (1974). Handbook on human nutritional requirements. Published by FAO, Rome, 53-63.

Guine, R. P. F. and M. J. Barroca (2012). Effect of drying treatments on texture and color of vegetables (pumpkin and green pepper).Food and Bioproducts Processing, 90: 58-63.

Hainida, E.; A. Ismail; N. Hashim and A. Zakiah (2008a). Effects of defatted dried roselle (Hibiscus sabdariffa L.) seed powder on lipid profiles of hypercholesterolemia rats. Journal of the Science of Food and Agriculture, 88: 1043-1050.

Hainida, K.; I. Amin; H. Normahand N. Mohd-Esa (2008b). Nutritional and amino acid contents of differently treated Roselle (Hibiscus sabdariffa L.) seeds. Food Chemistry, 111: 906-911.

Jia, C.; W. Huang; M. A. S. Abdel-Samie; G. Huang and G. Huang (2011). Dough rheological, Mixolab mixing, and nutritional characteristics of almond cookies with and without xylanase. Journal of Food Engineering, 105: 227-232.

Lee, J. H. and D. W. Choi (2013). Effects of the Addition of Ecklonia cava Powder on the Selected Physicochemical and Sensory Quality of White Pan Bread. Prev. Nutrition and Food Science, 18: 287-291. 
Lilei, Y. U.; A. L. Nanguet and T. Beta (2013). Comparison of Antioxidant Properties of Refined and Whole Wheat Flour and Bread. Antioxidants, 2: $370-383$

Mohamed, R.; J. Fernandez; M. Pineda and M. Aguilar (2007).Roselle (Hibiscus sabdariffa L.) Seed Oil Is a Rich Source of $y$ - Tocopherol. Journal of food science,72: 207-211.

Mohd-Esa, N.; F. S. Hern; A. Ismail; and C. L. Yee (2010).Antioxidant activity in different parts of roselle (Hibiscus sabdariffa L.) extracts and potential exploitation of the seeds. Food Chemistry, 122: 1055-1060.

O'Brien, C. M.; H. Grau; D. P. Neville; M. K. Keogh and E. K. Arendt (2000). Functionality of microencapsulated high-fat powders in wheat bread. European Food Research and Technology, 212: 64-69.

Ogur, S. (2014). Evaluation of amino acid changes and crumb hardness of enriched bread with tench (Tincatinca L.) flesh in turkey. Journal of Food and Nutrition Research,2: 985-992.

Onyango, C.; L. Unbehend; G. Unbehend and M. G. Lindhauer (2015). Rheological properties of wheat-maize dough and their relationship with the quality of bread treated with ascorbic acid and malzperle classic bread improver. African Journal of Food Science, 9: 84-91.

Perten, H. (1990). Rapid measurement of wet gluten quality by GI. Cereal Chemistry, 35: 401-408.

Rakszegi M.; G. Balázs; F. Békés; A. Harasztos; A. Kovács; L. Láng; Z. Bedő and S. Tömösközi (2014). Modelling water absorption of wheat flour by taking into consideration of the soluble protein and arabinoxylan components. Cereal Research Communications, 42(4):629-639.

Rosell, C. M.; C. Collar and M. Haros (2007). Assesment of hydrocolloid effects on the thermo-mechanical properties of wheat using the Mixolab. Food Hydrocolloids, 21: 452-462.

SAS Institute Inc. (1990). SAS/STAT User's Guide, Volume 2, Version 6, Fourth edition, Cary, NC: SAS Institute Inc.

Sciarini, L. S.; P. D. Ribotta; A. E. Leon and G. T. Perez (2012). Incorporation of several additives into gluten free breads: Effect on dough properties and bread quality. Journal of Food Engineering, 111: 590-597

Sedej, I.; M. Sakac; A. Mandic; A. Misan; V. Tumbas and M. Hadnadev (2011). Assessment of antioxidant activity and rheological properties of wheat and buckwheat milling fractions. Journal of Cereal Science, 54: 347-353.

Sibanda T.; T. Ncube and N. Ngoromani (2015). Rheological Properties and Bread Making Quality of White Grain Sorghum-Wheat Flour Composites. International Journal of Food Science and Nutrition Engineering, 5(4): 176-182.

Seleem, H. A. and A. A. Omran (2014). Evaluation Quality of One Layer Flat Bread Supplemented with Beans and Sorghum Baked on Hot Metal Surface. Food and Nutrition Sciences, 5: 2246-2256.

Swieca M.; L. Seczyk; U. G. Dziki and D. Dziki (2014).Bread enriched with quinoa leaves - The influence of protein-phenolics interactions on the nutritional and antioxidant quality. Food Chemistry, 162, 54-62. 
Tounkara, F.; T. Amza; C. Lagnika; G. W. Le and Y. H. Shi (2013). Extraction, characterization, nutritional and functional properties of Roselle (Hibiscus sabdariffa L.) seed proteins. Songklanakarin Journal of Science and Technology, 35: 159-166.

Tuorila, H. (2015). From sensory evaluation to sensory and consumer research of food: An autobiographical perspective. Food Quality and Preference, 40, 255-262.

Yagoub, A. E.; M. A. Mohammed and A. A. Abu Baker (2008). Effect of soaking, sprouting and cooking on chemical composition, bioavailability of minerals and in vitro protein digestibility of roselle (Hibiscus sabdariffa L.) seed. Pakistan Journal of Nutrition,7: 50-56.

Zhu, J.; S. Huang; K. Khan and L. O'Brien (2001). Relationship of Protein Quantity, Quality and Dough Properties with Chinese Steamed Bread Quality. Journal of Cereal Science, 33: 205-212.

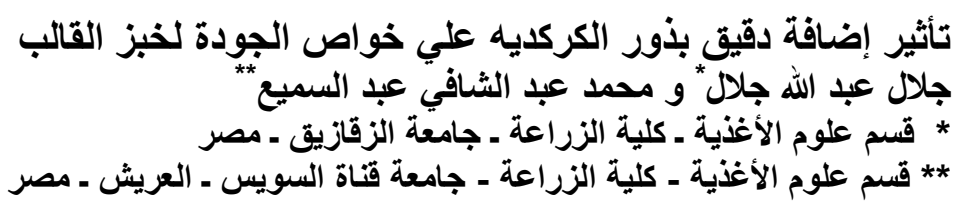

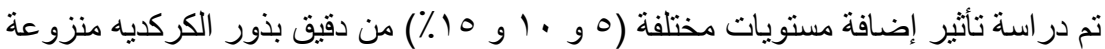

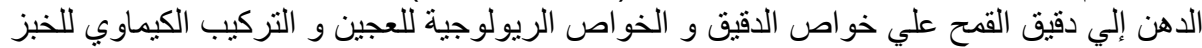

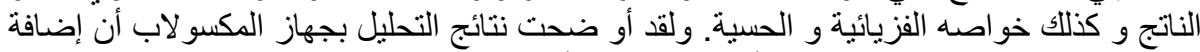

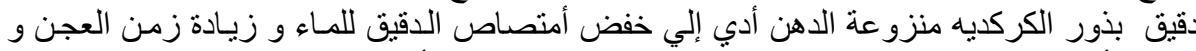

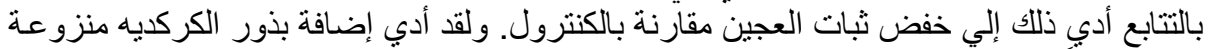

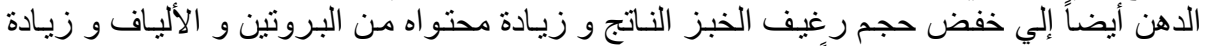

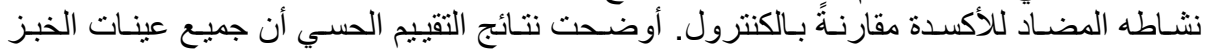

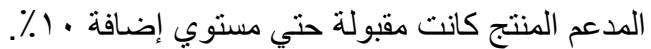

الكلمات المفتحية: تدعيم الخبز، دقيق بذور الكركديه، الخصائص الريولوجية، المكسو لاب 